\title{
ALAT CEKAT FUNGSIONAL JASPER JUMPER DALAM BIDANG ORTODONTI
}

\author{
Retno Widayati, Erwin Siregar \\ Bagian Ortodonti Fakultas Kedokteran Gigi Universitas Indonesia
}

Retno Widayati, Erwin Siregar. Alat cekat fungsional Jasper Jumper dalam bidang orthodonti. Journal Dentistry Indonesia 2004;11(1):35-39

\begin{abstract}
Jasper Jumper is an orthodontic appliance that belongs to fixed functional appliance. This appliance is

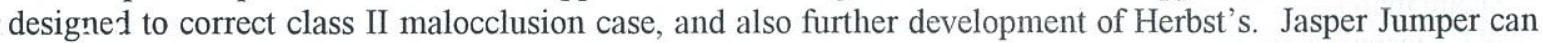
be used to move a tooth, a group of teeth, or the entire denture. In addition, this appliance can produce the same effect as headgear, activator, or any combination of them. Understanding of selected cases, biomechanics and the working mechanism of Jasper Jumper is very helpful for operators working with this appliance in clinics.
\end{abstract}

\section{Pendahuluan}

Selama lebih dari 80 tahun terakkhir, beberapa alat telah dikembangkan untuk merawat kasus maloklusi kelas II, seperti alat fungsional lepasan dan headgear. Keberhasilan perawatan menggunakan alat ini kendalanya sangat bergantung pada kooperatif pasien. Keadaan ini memungkinkan para ahli ortodonsi menaruh minat pada penggunaan alat cekat fungsional, terutama pada pasien yang kurang kooperatif.

Jasper Jumper adalah suatu alat ortodontik yang termasuk jenis alat cekat fungsional. Alat tersebut di desain untuk memperbaiki kasus maloklusi kelas II, dan merupakan pengembangan dari alat cekat fungsional Herbst. Keunggulan Jasper Jumper dibandingkan dengan Herbst, adalah mampu menghasilkan perubahan yang sama dengan Herbst, tetapi mempunyai konstruksi yang lebih fleksibel sehingga membe- rikan keleluasaan pada perlakuan untuk memposisikan mandibula. Jasper Jumper dapat digunakan untuk menggerakkan gigi, sekelompok gigi atau keseluruhan lengkung gigi, serta mampu menghasilkan efek yang sama dengan headgear, activator atau kombinasi keduanya.

Dengan dilatar belakangi hal-hal tersebut diatas, penulis merasa tertarik dan mengumpulkan beberapa kepustakaan guna memperoleh pengetahuan dan mempermudah pemahaman ten- 
tang segala sesuatu mengenai Jasper Jumper.

\section{Sejarah Perkembangan Jasper Jumper}

JasperJumper adalah suatu alat yang bekerja di antara maksila dan mandibula, berupa suatu koil yang analog dengan batang teleskop pada Herbst. Herbst sendiri pertama kali dipakai sebagai fixed bite jumping oleh Emil Herbst (1905) yang kemudian alat ini terus dikembangkan oleh Pancherz pada tahun $1977^{1,2}$. Herbst diindikasikan pada pasien usia tumbuh kembang dengan kasus skeletal dan dental kelas II serta deep overbite. Herbst mampu menghasilkan perubahan ortopedik aeñgan menstimulasi pertumbuhan mandibula dan menahan pertumbuhan maksila. Meskipun alat ini telah banyak dimodifikasi dengan desain banded, cast atau acrylic resin, konstruksinya yang kaku membatasi mekanisme kerja alat dan kenyamanan pasien ${ }^{3,4}$. Pada tahun 1987 Jasper membuat alat baru yang diilhami dengan prinsip dan cara kerja yang sama dengan Herbst, dengan konstruksi yang lebih fleksibel dikenal dengan Flexible Force Module atau Jasper Jumper ${ }^{5,6}$.

Cope $\mathrm{dkk}^{1}$ menyatakan bahwa koreksi kasus kelas II dengan Jasper Jumper terjadi karena peningkatan pertumbuhan kondilus mandibula, remodeling fossa glenoid ke bawah dan depan, menahan pertumbuhan maksila, retraksi dentoalveolar gigi-gigi atas serta ekspansi lateral gigi molar atas. Menurut Jasper ${ }^{1}$ ada 5 komponen yang mengkontribusi koreksi kelas II yaitu, $20 \%$ karena tertahannya pertumbuhan maksila, 20\% karena dentoalveolar maksila bergerak ke posterior, $20 \%$ karena pergerakan dentoalveolar mandibula ke depan, 20\% stimulasi pertumbuhan kondilus mandibula, dan $20 \%$ lagi remodeling fossa glenoid kebawah dan ke depan. Sedangkan Namara (1995), menguraikan bahwa alat ini menghasilkan vektor gaya dorong ke arah sagital dan vertikal (intrusi) ${ }^{5,6}$.

Penelitian mengenai efektifitas JasperJumper dilakukan oleh Rankin $(1991)^{8}$, kemudian Weiland dan Bantleon (1995) ${ }^{9}$, serta Weiland dan Droschl $(1996)^{10}$, pada anak anak umur 9 -12 tahun dengan maloklusi kelas II divisi 1. Kesimpulan hasil penelitian tersebut menunjukkan bahwa secara klinik dan secara sefalometri koreksi overjet, overbite, relasi molar dan relasi skeletal dikontribusi oleh $40 \%$ komponen skeletal dan $60 \%$ dental. Sedangkan penelitian Cope, Buschang (1994) ${ }^{11}$, menyimpulkan kontribusi faktor dental lebih besar daripada skeletal.

\section{Komponen Jasper Jumper}

Jasper Jumper terdiri dari 2 unit yaitu force module dan unit penjangkar. Kontruksi force module adalah stainless steel coil yang dilapisi polyurethane yang transparan. Pada ujung koil terdapat kapsul dari metal dan berlubang dan terdiri dari bagian mesial dan distal. Bagian distal terletak pada distal molar tube, bagian mesial pada archwire di distal kaninus bawah. Force module (Jasper Jumper) ini berfungsi mengakomodasikan unit penjangkar, tersedia dalam 7 ukuran dari 26-38 mm. Unit penjangkar adalah tempat peleakan lubang dari Jasper Jumper. Ada 2 macam unit penjangkar, yaitu yang terletak pada archwire utama, dan terletak pada archwire tambahan. Pada unit penjangkar yang terletak pada archwire utama (Gambar 1), gigi molar satu atas menggunakan face bow tube dengan 2 lubang. Lubang kearah servikal untuk archwire dan lubang ke arah oklusal untuk tempat peletakkan ball pin. Bagian distal Jasper Jumper terletak diantara ball pin dan molar tube. Sedangkan bagian mesialnya dimasukkan ke archwire di distal kaninus bawah yang dibuat tekukan bayonet dan stop small lexan bead. Sedangkan unit penjangkar yang terletak pada archwire tambahan, (Gambar 2), dipergunakan out triggers (0.016X0.022 pada 0.018 slot dan $0.018 \times 0.025$ pada 0.022 slot) sebagai auxillary sectional archwire berupa lup di regio distal kaninus bawah dan mesial molar satu bawah kiri dan kanan. letaknya sejajar dengan archwire utama.

\section{Mekanisme Kerja Jasper Jumper}

Jasper Jumper dikaitkan pada archwire. Alat tersebut pasit? pada saat Jasper Jumper lurus. Pada waktu gigi-gigi beroklusi, alat tersebut melengkung menghasilkan tekanan. Gaya dorong yang dihasilkan memandu mandibula ke arah depan dan bawah. Sesuai vektor gaya, terjadi distalisasi dan intrusi gigi molar atas, proklinasi dan intrusi gigi insisif bawah, serta stimulasi pertumbuhan pada kondilus 5,6,12,13. Karena alat ini juga melengkung ke arah bukal, memberi efek gaya transversal ${ }^{5,6}$.

Gigi molar dan anterior atas bergerak tiping ke posterior, meskipun seluruh gigi-gigi atas telah diikat sebagai kesatuan. Pergerakan tiping terjadi karena arah gaya Jasper Jumper berada di belakang dan di bawah unit center of resistance. Gigi molar 
bawah bergerak translasi dan tiping, karena gaya alat ini agak dekat dan sedikit diatas center of resistence gigi molar bawah ${ }^{11}$.

\section{Penatalaksanaan Jasper Jumper di klinik.}

Sebelum pemakaian Jasper Jumper, tahap awal adalah melakukan aligning dan leveling gigi-gigi atas dan bawah sampai archwire persegi ukuran besar. Distal archwire di cinched back,
Setelah archwire pasif, archwire bawah dibuatkan tekukan bayonet di distal breket kaninus bawah yang berfungsi sebagai stop. Breket gigi premolar satu dilepas, dan small lexan bead dimasukkan ke archwire di distal tekukan bayonet sisi kiri dan $\operatorname{kanan}^{5,6}$.

Pasien diinstruksikan pada posisi relasi sentrik, dan ukur jarak dari mesial face bow tube molar atas ke small lexan bead. Jarak tersebut ditambah $12 \mathrm{~mm}$ bagian distalnya pada tube molar atas dengan menggunakan ball pin. Ball pin dimasukkan dari distal, dan di cinched back di mesialnya. jarak distal tube ke bulatan pin adalah 2-3 mm. Pada keadaan ini, Jasper Jumper menghasilkan tekanan sebesar 4 ounces $(120 \mathrm{gr} / \mathrm{sisi})^{5,6}$.

Pada pemasangan awal, Jasper Jumper dalam keadaan pasif untuk memberikan kesempatan pasien beradaptasi, dengan cara meletakkan bulatan pin lebih
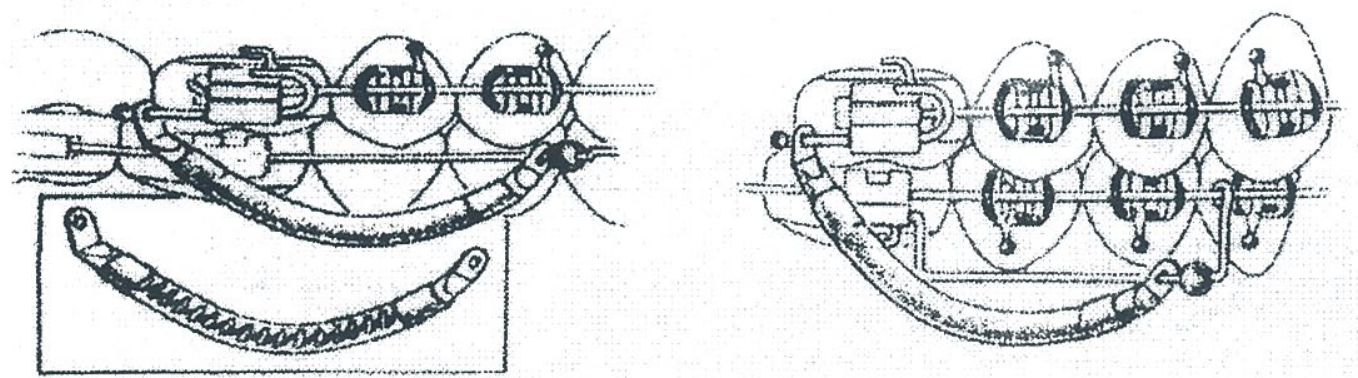

Gambar 1(kiri) : Letak Jasper Jumper pada archwire, bagian distal melalui ball pin. Dikutip dari AJO 1995, vol 108, No 6, hal 644

Gambar 2 (kanan) : Penggunaan outriggers untuk peletakan Jasper Jumper Dikutip dari Graber, Dentofacial orthopedic with functional appliances, $2^{\text {nd }}$ ed, 1997 , hal 370.
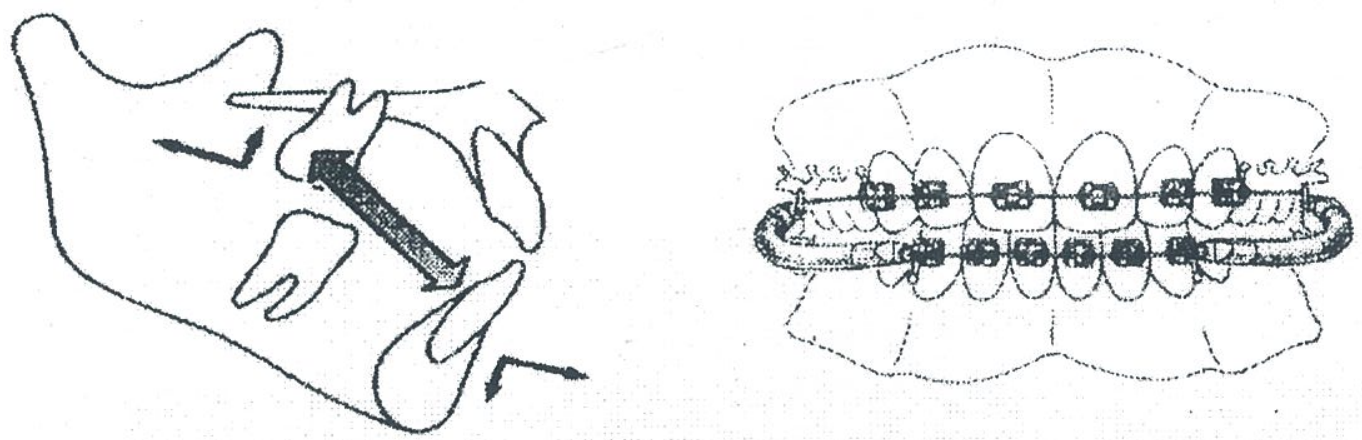

Gambar 3 (kiri) : Vektor gaya dorong yang dihasilkan Jasper Jumper dan Herbst. Dikutip dari AJO 1995, vol 108, No 6, hal 643 .

Gambar 4 (kanan) : Jasper Jumper melengkung ke bukal menghasilkan gaya transversal. Dikutip dari Graber, Dentofacial orthopedic with functional appliances, $2^{\text {nd }}$ ed, 1997, hal 373.

dan untuk meningkatkan penjangkaran dapat dilakukan tip back bend $^{1,12}$ adalah ukuran Jasper Jumper yang tepat. Letakkan bagian mesial alat tersebut di distal small lexan bead di archwire bawah dan ke distal. Kunjungan berikutnya dapat dilakukan aktivasi dengan memendekkan jarak bulatan ke distal tube. Aktivasi dilakukan 
interval 5-6 minggu. Aktivasi dapat dilakukan dengan beberapa cara. Yang pertama, pin ditarik ke mesial tube $1 \mathrm{~mm}$ dan di cinched back. Kedua, dengan jalan menambahkan crimpable stop yang diletakkan di mesial lexan ball. Jika masih diperlukan aktivasi, Jasper Jumper diganti dengan ukuran yang lebih besar ${ }^{6}$.

Pada pasien yang memiliki potensi tumbuh kembang dan diharapkan terjadi reposisi ortopedik mandibula, diguriakan tekanan yang lebih besar sekitar 6-8 ounces (180-250 gr/sisi $)^{5,6}$. Agar alat ini tetap stabil dan dapat bekerja dengan baik, pasien dianjurkan agar tidak membuka mulut terlalu lebar dan tidak mengkonsumsi diet yang keras. Jasper Jumper dipakai selama 68 bulan, dan dilanjutkan dengan finishing dengan alat cekat. Setelah tahap akhir Jasper Jumper tetap dipakai selama 3-4 bulan untuk. stabilisasi hasil yang telah dicapái. Retensi paska perawatan menggunakan Hawley retainer dan bonded retainer pada gigi anterior bawah ${ }^{9,10}$. Jasper Jumper juga dapat digunakan untuk meretraksi kaninus menggunakan elastomeric chain atau pegas NiTi yang dikaitkan pada pin di face bow tube dan breket kaninus, ataupun archwire di rahang atas untuk meretraksi enam gigi anterior $\operatorname{atas}^{5,6}$.

\section{Pembahasan}

Jasper Jumper dirancang untuk nemperbaiki kasus maloklusi kelas II. Maloklusi kelas II sendiri mempunyai beberapa konfigurasi skeletal dan dental. Menurut Cope $\mathrm{dkk}^{1}$, indikasi penggunaan Jasper Jumper pada kelas II dengan maksila protruded dan mandibula retruded, se- dangkan Weiland dan Bantleon", menyatakan indikasinya pada maloklusi kelas II divisi 1 dengan mandibula retruded dan deep bite. Diantara kedua pendapat tersebut, penting diperhatikan adanya perbedaan indikasi maksila yang protruded dan normal. Berdasarkan hasil penelitian Cope dkk ${ }^{1}$, titik ANS, PNS, A, PTM memang mengalami perpindahan ke posterior, tetapi jika dibandingkan dengan kelompok kontrol secara statistik perubahan tersebut tidak bermakna. Atau perubahan yang terjadi pada titik A dan ANS merupakan refleksi dari posisi gigi insisif atas yang teretraksi karena perawatan. Karena efek Jasper Jumper dalam menahan pertumbuhan maksila sangat kecil, maka penggunaannya terbatas pada kasus kelas II dengan protruded ringan.

Hal kedua yang perlu diperhatikan adalah unit penjangkar yang merupakan bagian terpenting dari sistem alat ini. Untuk mendapatkan efek headgear seperti distalisasi dan intrusi molar atas, rahang bawah harus dimaksimalkan sebagai unit penjangkar. Upaya untuk meningkatkan penjangkaran di rahang bawah dengan menambahkan lingual holding arch, penggunaan breket preadjusted, archwire persegi ukuran besar $(0.021 \mathrm{X} 0.025)$, serta archwire bawah di tip back bend $^{12}$. Archwire atas dibiarkan lurus beberapa $\mathrm{mm}$ dari distal tube. Karena gaya yang diberikan oleh Jasper Jumper ditahan oleh seluruh gigi bawah, maka pada rahang bawah terjadi perubahan yang minimal, perubahan terbesar terjadi pada gigi molar atas yang terdistalisasi sekaligus terintrusi. Untuk memperoleh efektifitas seperti alat fungsional lainnya dalam reposisi mandibula ke depan, rahang atas harus diupayakan sebagai unit penjang- kar maksimal. Hal ini dapat dicapai dengan menambahkan transpalatal arch, archwire persegi ukuran besar $(0.021 \times 0.025)$ dan di tip back bend ${ }^{12}$. Gaya yang diberikan oleh Jasper Jumper ditahan oleh seluruh gigi atas, dan ditransfer ke gigi-gigi bawah dan mandibula, ${ }^{5,6,11}$. Dalam hal ini penting diperhatikan prosedur aktivasi dan besar tekanan yang dipergunakan yang disesuaikan dengan kebutuhan yang diinginkan.

Sehubungan dengan dampak intrusi yang terjadi, penting diperhatikan kontra indikasi penggunaan alat ini yaitu pada kasuskasus yang memiliki predisposisi resorpsi akar dan openbite dental dan skeletal. Demikian juga pada kelas II dengan sudut bidang mandibula yang besar dan tinggi muka bawah yang besar. Hal ini disebabkan karena adanya kecenderungan terjadi rotasi mandibula ke bawah dan ke belakang, sehingga dapat menambah tinggi muka bawah yang besar yang mempengaruhi estetika dan stabilitas paska perawatan ${ }^{5,11,13}$.

Hagg dan Pancherz, menyarankan perawatan maloklusi kelas II sebaiknya dimulai pada periode puncak pertumbuhan pubertas, karena pada waktu tersebut pengaruh terhadap pertumbuhan kondilus mandibula sangat baik, dan diharapkan dapat memperoleh perubahan ortopedik yang besar $^{14}$. Mengingat waktu perawatan dengan Jasper Jumper sangat singkat ( 6-8 bulan ), maka pemakaian alat tersebut dapat ditunda sampai awal periode setelah pertumbuhan puncak atau sampai awal erupsi gigi permanen. Hal ini bertujuan untuk mendapatkan stabilitas oklusal yang lebih baik dan mengurangi waktu pemakaian retensi ${ }^{12,14}$. 


\section{Kesimpulan}

Jasper Jumper adalah alat cekat fungsional di bidang ortodonti, di indikasikan pada anakanak usia tumbuh kembang dengan kasus skeletal kelas II (maksila normal, mandibula retruded), deep overbite dan tinggi muka bawah normal. Jasper Jumper merupakan suatu alat alternatif jika pasien memiliki masalah tidak kooperatif dan menolak perawatan dengan alat fungsional lepasan, atau mempunyai masalah bernafas melalui mulut.

Pemahaman mengenai seleksi kasus, biomekanika dan mekanisme kerja Jasper Jumper sangat membantu operator dalam penatalaksanaan Jasper Jumper di klinik.

Penemuan dan penggunaan alat ini relatif masih baru, masih diperlukan penelitian lebih lanjut untuk mengevaluasi efektifitas hasil perawatan pada periode paska perawatan yang lebih lama.

\section{Daftar Pustaka}

1. Mills Mc Culloch. Case report: Modified use of the Jasper Jumper appliance in a skeletal class II mixed dentition case requiring palatal expansion. Angle orthod 1997.67(4):277-82.

2. Mc Namara JA, Brudon WL. Orthodontic and Orthopedic treatment in the mixed dentition, $4^{\text {th }}$ ed. Nedham press, Michigan. 1994: 259-63.

3. Pancherz H. The Herbst appliance its biologic effets and clinical use. AJO 1985. 87(1):118.

4. Smith JRB. Matching the Herbst to the malocclusion. $J$ Clin Imp 1999. 8(1): 17.

5. Graber TM, Rakosi T, Petrovic AG. Dentofacial orthopedics with functional aplliances. 2 nd ed. CV Mosby Co. 1997: 367-75.

6. Jasper JJ, Mc Namara. The correction of interarch malocclusions using a fixed force module. AJO and dentofac ortp 1995. 108(6): 641-9.

7. Namara JA. Components of class II malocclusion in children 8-10 years of age. Angle orthod 1981. 51(3): 177-80, 196-200.
8. Rankin $\mathrm{TH}$. Correction of class II malocclusion with a fixed functional appliance. AJO 1991. 100: 390.

9. Weiland FJ, Bantleon HP. Treatment of class II malocclusion with the Jasper Jumper appliance- a preliminary report. AJO 1995. 108(4).341-50.

10. Weiland FJ, Droschl. Treatment of class II division 1 malocclusion with the Jasper Jumper a case report. AJO 1996.109 (1): 1-7.

11. Cope TB, Buschang PH, ParkerJ, Blackwood HO. Quantitative evaluation of craniofacial changes with Jasper Jumper therapy. Angle orthod 1994.64(2): 11322.

12. Blackwood. Clinical management of the Jasper Jumper. JCO 1991: 25(12): 755-60.

13. Woodside, Metaxas A, Altuna G. The influence of functional appliance therapy on glenoid fossa remodeling. AJO 1987..92 (3): 181-95.

14. King GJ et al. The timing of treatment for class II malocclusion in children: Literatur view. Angle orthod 1989.60 (2): 87-92. 